\title{
Comparison of Esophageal Cancer Incidence between the Eastern Anatolia and Eastern Black Sea Regions
}

\author{
Mustafa KANDAZ \\ Department of Radiation Oncology, Karadeniz Technical University Faculty of Medicine, Trabzon-Turkey
}

\begin{abstract}
OBJECTIVE
Incidence of esophageal cancer varies among countries, with differences found particularly between developed and less-developed regions. The aim of the present study was to investigate differences in incidence between the Eastern Anatolia Region (EAR) and the Eastern Black Sea Region (EBSR).

\section{METHODS}

Data were obtained from the databases of the EAR (1996-2010) and the EBSR (1999-2013). A total of 47 patients from the EBSR and 135 patients from the EAR were included.

\section{RESULTS}

Higher incidence of esophageal cancer was found in the EAR, compared to the EBSR. In the EAR, overall survival was 20 months, median survival was 13 months, and 1-, 3-, and 5-year survival rates were $51.3 \%, 20.1 \%$, and $13.4 \%$, respectively. Following termination of treatment, overall survival was 18 months in the EBSR, median survival was 12 months, and 1-, 3-, and 5-year survival rates were 52.5\%, $10.9 \%$, and $6.6 \%$, respectively.
\end{abstract}

\section{CONCLUSION}

A significant difference was found between regions regarding incidence of esophageal cancer. This cancer may be prevented through public education and awareness. Programs that promote prevention must be implemented worldwide, particularly in the EAR.

Keywords: Esophageal cancer; epidemiology; Eastern Anatolia Region, Eastern Black Sea Region.

Copyright $\odot$ 2016, Turkish Society for Radiation Oncology

\section{Introduction}

Esophageal cancer is diagnosed at a rate of 5\% among all cancers, and is the sixth most common cause of cancer mortality. Average annual incidence is 5:100,000.[1] Incidence of cancer varies around Turkey, with distinct differences particularly found between developed and less-developed regions. While the national mean rate is $1.7 \%$, it is increased to $16 \%$ in the Eastern Anatolia Region (EAR). Demographic, ecological, environmental, cultural, and genetic variables all contribute to the het- erogeneity of cancer incidence. Genetic factors and excessive consumption of hot drinks and food, and nitriteand nitrosamine-containing foods, have been thought to contribute.[2] However, little information is available regarding cancer in less-developed countries. Patterns of cancer incidence can provide important insights into the impact of lifestyle on cancer development.

The aim of the present comparison of cancer incidence between the EAR and the Eastern Black Sea Region (EBSR) was to provide useful information in 
an effort to determine requirements for cancer prevention and control.

\section{Materials and Methods}

The present data were obtained from the EAR 19962010 and the EBSR 1999-2013 databases. A total of 47 patients in the EBSR and 135 patients in the EAR were enrolled. Sex (male / female), age $(\leq 60 />60)$, Karnofsky performance status (KPS), localization (upper / middle / lower), histology (squamous cell carcinoma (SCC) / adenocarcinoma (ADC) / other), stage of disease (TNM), and treatment modality were noted. Data analysis was performed using SPSS software (version

Table 1 Patient characteristics

\begin{tabular}{|c|c|c|c|c|}
\hline & $\begin{array}{c}\text { EAR } \\
(n)\end{array}$ & $\begin{array}{c}\text { EBSR } \\
(n)\end{array}$ & $\begin{array}{c}\text { EAR } \\
(\%)\end{array}$ & $\begin{array}{c}\text { EBSR } \\
(\%)\end{array}$ \\
\hline \multicolumn{5}{|l|}{ Sex } \\
\hline Male & 65 & 35 & 48 & 74 \\
\hline Female & 70 & 12 & 52 & 26 \\
\hline \multicolumn{5}{|l|}{ Age } \\
\hline$\leq 60$ & 69 & 21 & 51 & 45 \\
\hline$\geq 61$ & 66 & 26 & 49 & 55 \\
\hline \multicolumn{5}{|l|}{ Smoking } \\
\hline No & 77 & 25 & 43 & 53 \\
\hline Yes & 58 & 22 & 57 & 47 \\
\hline \multicolumn{5}{|l|}{ Family History } \\
\hline No & 125 & 47 & 93 & 100 \\
\hline Yes & 10 & 0 & 7 & 0 \\
\hline \multicolumn{5}{|l|}{ KPS } \\
\hline 60 & 5 & 5 & 4 & 10 \\
\hline 70 & 34 & 15 & 25 & 32 \\
\hline 80 & 49 & 13 & 36 & 28 \\
\hline$\geq 90$ & 47 & 14 & 35 & 30 \\
\hline \multicolumn{5}{|l|}{ Localization } \\
\hline Upper & 25 & 5 & 19 & 10 \\
\hline Middle & 34 & 3 & 25 & 7 \\
\hline Lower & 76 & 39 & 56 & 83 \\
\hline \multicolumn{5}{|l|}{ Histology } \\
\hline SCC & 129 & 42 & 96 & 89 \\
\hline ADK & 5 & 4 & 3 & 9 \\
\hline Other & 1 & 1 & 1 & 2 \\
\hline \multicolumn{5}{|l|}{ Stage } \\
\hline II & 19 & 17 & 14 & 36 \\
\hline III & 90 & 25 & 67 & 54 \\
\hline IV & 26 & 5 & 19 & 10 \\
\hline \multicolumn{5}{|l|}{ Life Situation } \\
\hline Alive & 30 & 3 & 22 & 7 \\
\hline Dead & 90 & 44 & 67 & 93 \\
\hline Unknown & 15 & - & 11 & - \\
\hline
\end{tabular}

13.0; SPSS Inc., Chicago, IL, USA). The Kaplan-Meier test was used for survival analysis, and the log-rank test was used to determine potential prognostic significance of variables in order to assess effects on survival.

\section{Results}

Patient characteristics are shown in Table 1. Prevalence of esophageal cancer is higher among females in the EBSR and among males in the EAR.

Risk of EAR was increased in patients under 60 years of age. A similarity was found regarding smoking and performance status among the regions. While the EBSR was not associated with familial predisposition, the EAR was associated with an incidence ratio of 7:100. The most common histology was SCC, and the primary site of tumor was the lower esophagus in both regions. Ratio of EBSR patients with stage 4 was 1:10,

$\begin{array}{ccccc}\text { Table } 2 & \text { Treatment characteristics } \\ & \text { EAR } & \text { EBSR } & \text { EAR } & \text { EBSR } \\ & (n) & (n) & (\%) & (\%)\end{array}$

\begin{tabular}{lcccc}
\hline Treatment & & & & \\
No & 2 & 1 & 2 & 2 \\
RT & 29 & 16 & 21 & 34 \\
CRT & 63 & 17 & 47 & 36 \\
S+RT & 9 & 3 & 7 & 7 \\
S+CRT & 10 & 9 & 7 & 19 \\
Palliative & 22 & 1 & 16 & 2 \\
CT Cure & & & & \\
No & 53 & 19 & 39 & 40 \\
1 cure & 21 & 21 & 16 & 45 \\
2 cure & 53 & 4 & 39 & 9 \\
3 & 8 & 3 & 6 & 6 \\
CT Protocol & & & & \\
No & 53 & 19 & 39 & 40 \\
Cisplatin+5-FU & 71 & 21 & 52 & 45 \\
Cisplatin (weekly) & 9 & 4 & 7 & 9 \\
Other & 2 & 3 & 2 & 6 \\
RT Dose & & & & \\
No & 2 & 2 & 2 & 4 \\
30 Gray & 21 & 11 & 16 & 23 \\
45 Gray & 29 & 5 & 21 & 11 \\
50.4 Gray & 45 & 12 & 33 & 26 \\
54 Gray & 11 & 3 & 8 & 6 \\
60 Gray & 12 & 7 & 9 & 15 \\
Other & 15 & 7 & 11 & 15 \\
Surgery & & & & \\
No & 92 & 35 & 68 & 74 \\
Yes & 34 & 12 & 25 & 26 \\
Pre-operative & 9 & 0 & 7 & 0 \\
\hline
\end{tabular}


Table 3 Survival analysis

\begin{tabular}{|c|c|c|c|c|c|c|c|c|c|c|c|c|c|c|}
\hline & \multicolumn{2}{|c|}{$\mathbf{n}$} & \multicolumn{2}{|c|}{$\begin{array}{l}\text { Median } \\
\text { survival } \\
\text { period } \\
\text { (month) }\end{array}$} & \multicolumn{2}{|c|}{$\begin{array}{l}\text { Average } \\
\text { survival } \\
\text { period } \\
\text { (month) }\end{array}$} & \multicolumn{2}{|c|}{$\mathbf{p}$} & \multicolumn{2}{|c|}{$\begin{array}{c}\text { Survival } \\
\text { rate } \\
1 \text { year } \\
(\%)\end{array}$} & \multicolumn{2}{|c|}{$\begin{array}{c}\text { Survival } \\
\text { rate } \\
3 \text { years } \\
(\%)\end{array}$} & \multicolumn{2}{|c|}{$\begin{array}{c}\text { Survival } \\
\text { rate } \\
5 \text { years } \\
(\%)\end{array}$} \\
\hline & EAR & EBSR & EAR & EBSR & EAR & EBSR & EAR & EBSR & EAR & EBSR & EAR & EBSR & EAR & EBSF \\
\hline $\begin{array}{l}\text { General } \\
\text { Sex }\end{array}$ & 135 & 47 & $13 \pm 1$ & $12 \pm 2$ & 20 & 18 & & & 51.3 & 52.5 & 20.1 & 10.9 & 13.4 & 6.6 \\
\hline Female & 70 & 12 & $13 \pm 2$ & $14 \pm 3$ & 22 & 25 & & & 51.5 & 58.3 & 27.8 & 16.7 & 18.5 & 8.3 \\
\hline $\begin{array}{l}\text { Male } \\
\text { Age }\end{array}$ & 65 & 35 & $13 \pm 1$ & $10 \pm 2$ & 16 & 15 & 0.421 & 0.219 & 51.1 & 47.5 & 15.6 & 8.9 & 10.4 & 3.0 \\
\hline$\leq 60$ & 69 & 21 & $15 \pm 2$ & $10 \pm 2$ & 23 & 18 & & & 60.2 & 42.9 & 30.3 & 14.3 & 15.1 & 4.8 \\
\hline $\begin{array}{l}\geq 61 \\
\text { KPS }\end{array}$ & 66 & 26 & $11 \pm 1$ & $12 \pm 2$ & 15 & 16 & 0.021 & 0.651 & 40.7 & 48.7 & 14.6 & 8.1 & 9.7 & 4.1 \\
\hline 60 & 5 & 5 & $8 \pm 1$ & $2 \pm 0.5$ & 9 & 2 & & & 20.0 & 0 & 0 & 0 & 0 & 0 \\
\hline 70 & 34 & 15 & $8 \pm 1$ & $7 \pm 3$ & 8 & 5 & & & 16.9 & 0 & 0 & 0 & 0 & 0 \\
\hline 80 & 49 & 13 & $14 \pm 1$ & $14 \pm 1$ & 19 & 12 & & & 62.5 & 53.8 & 11.1 & 0 & 0 & 0 \\
\hline $\begin{array}{l}90 \text { and } \uparrow \\
\text { Smoke }\end{array}$ & 47 & 14 & $21 \pm 3$ & $29 \pm 4$ & 29 & 40 & 0.001 & 0.001 & 70.0 & 92.9 & 42.4 & 35.7 & 38.5 & 14.3 \\
\hline $\begin{array}{l}\text { No } \\
\text { Yes }\end{array}$ & 77 & 25 & $14 \pm 2$ & $14 \pm 4$ & 22 & 21 & & & 56.3 & 50.5 & 24.8 & 12.6 & 16.5 & 0 \\
\hline $\begin{array}{l}58 \\
\text { Loc. }\end{array}$ & 22 & $11 \pm 1$ & $8 \pm 2$ & 15 & 14 & 0.122 & 0.243 & 44.0 & 40.9 & 18.0 & 9.1 & 13.5 & 0 & \\
\hline Upper & 25 & 5 & $19 \pm 2$ & $12 \pm 2$ & 25 & 13 & & & 70.2 & 60.0 & 29.2 & 0 & 0 & 0 \\
\hline Middle & 34 & 3 & $10 \pm 1$ & $6 \pm 2$ & 18 & 5 & & & 47.1 & 0 & 32.1 & 0 & 27.5 & 0 \\
\hline $\begin{array}{l}\text { Lower } \\
\text { Histo. }\end{array}$ & 76 & 39 & $11 \pm 1$ & $12 \pm 3$ & 17 & 19 & 0.370 & 0.107 & 46.2 & 47.7 & 17.0 & 13.2 & 14.1 & 5.3 \\
\hline SCC & 129 & 42 & $13 \pm 1$ & $12 \pm 3$ & 20 & 18 & & & 51.4 & 45.2 & 22.9 & 11.9 & 15.3 & 4.8 \\
\hline $\mathrm{ADC}$ & 5 & 4 & $19 \pm 1$ & $10 \pm 3$ & 17 & 12 & & & 60.0 & 25.0 & 0 & 0 & 0 & 0 \\
\hline $\begin{array}{l}\text { Other } \\
\text { Stage }\end{array}$ & 1 & 1 & 8 & $12 \pm 2$ & 8 & 18 & 0.605 & 0.661 & 0 & 0 & 0 & 0 & 0 & 0 \\
\hline II & 19 & 17 & $19 \pm 3$ & $27 \pm 2$ & 21 & 34 & & & 64.3 & 88.2 & 21.4 & 29.4 & 14.3 & 11.8 \\
\hline III & 90 & 25 & $14 \pm 1$ & $7 \pm 1$ & 23 & 9 & & & 56.9 & 32.0 & 30.1 & 0 & 20.1 & 0 \\
\hline $\begin{array}{l}\text { IV } \\
\text { Treat. }\end{array}$ & 26 & 5 & $9 \pm 1$ & $4 \pm 1$ & 8 & 5 & 0.002 & 0.001 & 25.0 & 0 & 4.2 & 0 & 0 & 0 \\
\hline No & 2 & 1 & $2 \pm 0$ & - & 3 & - & & & 0 & - & 0 & - & 0 & - \\
\hline RT 29 & 16 & $10 \pm 1$ & $8 \pm 3$ & 15 & 16 & & & 35.3 & 43.8 & 12.6 & 12.5 & 0 & 0 & \\
\hline CRT & 63 & 17 & $19 \pm 2$ & $14 \pm 3$ & 24 & 20 & & & 67.2 & 52.9 & 33.2 & 11.8 & 29.9 & 11.8 \\
\hline $\mathrm{S}+\mathrm{RT}$ & 9 & 3 & $34 \pm 0$ & $7 \pm 1$ & 26 & 25 & & & 75.0 & 33.3 & 0 & 0 & 0 & 0 \\
\hline $\mathrm{S}+\mathrm{CRT}$ & 10 & 9 & $14 \pm 1$ & $10 \pm 4$ & 23 & 14 & & & 60.0 & 33.3 & 50.0 & 11.1 & 37.5 & 0 \\
\hline Pal. RT & 22 & 0 & $8 \pm 1$ & - & 8 & - & & & 18.2 & - & 0 & - & 0 & - \\
\hline CT & 0 & 1 & - & - & - & - & 0.001 & 0.917 & - & - & - & - & - & - \\
\hline$C T$ & & & & & & & & & & & & & & \\
\hline No & 53 & 19 & $9 \pm 6$ & $12 \pm 4$ & 11 & 18 & & & 27.6 & 47.4 & 4.4 & 15.8 & 0 & 5.3 \\
\hline Cis-FU & 71 & 22 & $19 \pm 1$ & $14 \pm 4$ & 26 & 20 & & & 67.6 & 53.1 & 36.1 & 9.7 & 32.8 & 9.7 \\
\hline W. Cis & 9 & 4 & $9 \pm 3$ & $7 \pm 5$ & 11 & 8 & & & 44.4 & 25.0 & 11.1 & 0 & 0 & 0 \\
\hline FUFA & 2 & 2 & $3 \pm 0$ & 7 & 6 & 8 & 0.001 & 0.405 & 0 & 0 & 0 & 0 & 0 & 0 \\
\hline $\mathrm{RT}$ & & & & & & & & & & & & & & \\
\hline No & 2 & 2 & $2 \pm 0$ & $16 \pm 0$ & 2 & 16 & & & 0 & 0 & 0 & 0 & 0 & 0 \\
\hline $0-3000$ & 21 & 11 & $8 \pm 1$ & $3 \pm 1$ & 8 & 8 & & & 15.0 & 9.1 & 0 & 0 & 0 & 0 \\
\hline 4500 & 29 & 5 & $16 \pm 4$ & $7 \pm 1$ & 23 & 10 & & & 63.2 & 20.0 & 27.6 & 0 & 13.8 & 0 \\
\hline 5040 & 45 & 12 & $21 \pm 2$ & $18 \pm 8$ & 29 & 30 & & & 75.6 & 83.3 & 40.4 & 16.7 & 36.3 & 16.7 \\
\hline 5400 & 11 & 3 & $9 \pm 7$ & $12 \pm 4$ & 11 & 16 & & & 50.0 & 33.3 & 40.0 & 0 & 30.0 & 0 \\
\hline 6000 & 12 & 7 & $13 \pm 5$ & $7 \pm 1$ & 17 & 16 & & & 60.0 & 28.6 & 30.0 & 14.3 & 15.0 & 0 \\
\hline $6000 \uparrow$ & 15 & 7 & $1 \pm 0$ & $14 \pm 7$ & 4 & 21 & 0.001 & 0.062 & 8.3 & 57.1 & 0 & 14.3 & 0 & 0 \\
\hline
\end{tabular}


while that of EAR patients was 1:10.

Treatment characteristics are shown in Table 2; the characteristics of both regions were substantially similar.

Survival analysis is shown in Table 3, and prognostic factors were also determined. In patients with esophageal cancer in the EAR, age, KPS, stage, treatment modality, chemotherapy protocol, number of cures, and general survival rates were found to be the prognostic factors related to the survival period in univariate analysis $(p<0.05)$. In patients with esophageal cancer in the EBSR, KPS, stage, and general survival rate were found to be the prognostic factors related to the survival period in univariate analysis $(\mathrm{p}<0.05)$.

\section{Discussion}

Esophageal cancer carries high rates of mortality and morbidity, and is the sixth most common cause of cancer mortality worldwide.[3] While not very common in Turkey, incidence is higher in the EAR, where it is a significant cause of cancer mortality. [4] This can be explained by geographic predisposition and environmental exposure.[2]

Esophageal cancer is more common in men worldwide. In the present patient population, the female:male ratio was 1.1:1 in the EAR and 2.9:1 in the EBSR. Early age at diagnosis among women in the EAR can be attributed to environmental exposure (use of tandoor and manure, hot food consumption) and to geographical predisposition.[2]

Average age at occurrence is 67 , with a peak in the 7th decade.[5] Average age in the EAR was 59 (59 in men, 58 in women). Average age in the EBSR was 61 (62 in men, 61 in women). SCC and ADC histological types are 95\% for the esophagus. [6] SCC and ADC histological types of both regions were determined as $99 \%$ in the present study.

Tumor localization is an important factor in prognosis. While upper-third esophageal cancer rarely occurs, survival is better than that of patients with esophageal cancer in the lower two-thirds.[7] In the present study, median survival was improved in patients with upper-third esophageal cancer, compatible with the literature.

Following termination of treatment, overall survival was 20 months in the EAR, median survival was 13 months, and survival rates at 1,3 , and 5 years were $51.3 \%, 20.1 \%$, and $13.4 \%$, respectively. Following ter- mination of treatment, overall survival was 18 months in the EBSR, median survival was 12 months, and survival rates at 1,3 , and 5 years were $52.5 \%, 10.9 \%$, and $6.6 \%$, respectively.

It was determined in the present retrospective analysis that the best survival in patients with inoperable esophageal cancer was obtained following 50.4 Gy radiotherapy with concurrent chemotherapy. In light of this information, we have adopted this clinical protocol as routine application.

\section{Conclusion}

Significant differences in esophageal cancer incidence were found between the regions. Esophageal cancer may be prevented through public education and awareness. Programs to promote esophageal cancer prevention should be globally implemented, particularly in the EAR.

\section{Disclosure Statement}

The authors declare no conflicts of interest.

\section{References}

1. Semnani SH, Besharat S, Abdolahi N. Esophageal cancer in northeastern Iran. Indian J Gastroenterol 2005;24:224-34.

2. Türkdoğan MK. Doğu Anadolu Bölgesinde üst gastrointestinal kanserlerinde beslenme ve çevre ile ilgili risk faktörleri. Hepato-gastroenteroloji sempozyumu 2003.

3. Ferguson MK. Neoplasm of esophagus. In: Cancer Medicine. 5th ed. BC Decker Inc. Lewiston; New York: 2000. p. 1334-54.

4. Zeng Q, Zhao Y, Yang Y, Zheng G, Wang G, Zhang P, et al. Expression of cystatin $C$ in human esophageal cancer. Tumori 2011;97(2):203-10.

5. Ries LAG, Eisner MP, Kosary C. SEER cancer statistics review, 1973-1999. Bethesda, Md. Natioanl Cancer Institute, 2002.

6. Daly JM, Fry WA, Little AG, Winchester DP, McKee RF, Stewart AK, et al. Esophageal cancer: results of an American College of Surgeons Patient Care Evaluation Study. J Am Coll Surg 2000;190(5):562-73.

7. Uğur V, Kara P, Küçükplakçı B, Demirkasımoğlu T, Özgen A. The Evaluation of General Characteristic and Radiotherapy Results of Esophageal Carcinoma Patients. Acta Oncologica Turcica 2005;102:9-15. 